\title{
A STUDY TO ASSESS THE KNOWLEDGE REGARDING VACCINE PREVENTABLE DISEASES AMONG THE MOTHERS OF UNDER FIVE CHILDREN AT RURAL AREA OF JAIPUR DISTRICT WITH VIEW TO DEVELOP AN INFORMATION BOOKLET
}

\author{
Vishnu Kumar ${ }^{1}$, Suresh ${ }^{2}$ \\ ${ }^{l}$ Nursing Officer, Banaras Hindu University Varanasi (UP) \\ ${ }^{2}$ Lecturer, K.S. Memorial College of Nursing, Jodhpur
}

Article DOI: https://doi.org/10.36713/epra9278

DOI No: 10.36713/epra9278

\begin{abstract}
INTRODUCTION: Children are the world's most valuable assets and their wellbeing indicates the standard of living of the country. They constitute one third of the total population. It has been noticed that almost one out of every five live born infants die before reaching 5 years of age. Immunisation is one of the most important weapons for protecting individuals and the community from serious diseases. The Department's immunisation team supports the public and health professionals by offering clear, evidence-based information about different diseases, the possible side effects of immunization and available vaccines.

AIM OF THE STUDY: Assess the knowledge regarding vaccine preventable disease among mothers of under five children.

METERIAL AND METHOD: A descriptive study was carried out to assess the knowledge of 60 mothers selected by purposive sampling, were assessed by using a structured knowledge questionnaire and analyzed by using descriptive and inferential statistics were used for data analysis.

RESULT: The findings of the study reveals that to the level of knowledge shows that majority of 60 mothers of under five children in which (33) 55\% had below average knowledge, (18) 30\% had average knowledge and (9) $15 \%$ of them had above average knowledge regarding vaccine preventable diseases.

CONCLUSION: It can be concluded that mothers have below average knowledge regarding vaccine preventable diseases as per current research recommendations. They require education and to enhance their knowledge regarding vaccine preventable diseases. Self-information booklets were distributed to them to improve the knowledge regarding vaccine preventable diseases

KEY WORDS: Awareness, knowledge, mothers, vaccine, information booklet.
\end{abstract}

\section{INTRODUCTION \& BACKGROUND OF THE STUDY}

Awareness building about immunization of children, who are under five years of age, provides a sense of responsibility towards the need of the children and their protection. Mothers' participation and involvement makes power in the home and for the children. Mothers in the rural areas being both economically and socially backward are ignorant and negligent in the aspects of health. They do not vaccinate the children, only because of some mild illness during the visit to the area. Some mothers fear the outcomes of the vaccination whereas few others express views upon religious thoughts. It is essential to screen every child for immunization, coverage opportunities; otherwise full immunization at every coverage may not be possible. Delayed immunization is associated with low socio-economic status, female illiteracy, lack of exposure to knowledge on Vaccine Preventable Diseases as recommended by Universal 


\section{EPRA International Journal of Research and Development (IJRD)}

Immunization Programme (UIP). In India children get the diseases at an early age in communities with low immunization coverage. This amounts to 25 to 33 per cent of all cases being children below one year of age and more than $2 / 3 \mathrm{rd}$ of children below 2 years of age.

Immunization is a proven tool for controlling and eliminating life-threatening infectious diseases and is estimated to avert between 2 and 3 million deaths each year. It is one of the most costeffective health investments, with proven strategies that make it accessible to even the most hard-to-reach and vulnerable populations. It has clearly defined target groups; it can be delivered effectively through outreach activities; and vaccination does not require any major lifestyle change. Immunization forms one of the most important and cost effective strategies for the prevention of childhood sicknesses and disabilities and is thus a basic need for all children. Immunization coverage levels of 69 to 82 percent with various vaccines were reported in 1989-90. While the priority remains to increase immunization coverage levels, surveillance of vaccine preventable diseases is receiving high priority to identify weak pockets for intensification of immunization services and to document impact. The achievements in a large number of districts show that the goal of universal immunization, while difficult and challenging, is attainable

Efforts are also on to improve health infrastructure in the country: key to optimize the implementation of UIP. National Rural Health Mission (NRHM) was launched in 2005 to re-vitalize the primary health care systems for the benefit of the people living in rural areas, particularly in difficult, inaccessible and remote parts of the country. Since the launch of NRHM in 2005, more than 15 billion dollars have been provided to the States in addition to their budgets, for strengthening health systems and infrastructure with key focus on reproductive and child health, including immunization.

Availability of new safe and effective vaccines against major killers like diarrhoea and pneumonia necessitated serious deliberations on further strengthening of National Immunization Programme. The Ministry of Health and Family Welfare formulated National Vaccine Policy in April 2011 to provide broad policy guidelines and framework to guide the creation of evidence base to justify need of research and development, production, procurement and quality assessment of vaccines under UIP.

The investigator's personal experience during her studies that many mothers of under five children in the rural area were found inappropriate knowledge. Majority of mothers are illiterates, labourers and having inadequate knowledge in vaccine preventable diseases. In light of the above facts, the investigator finds it necessary to assess the knowledge of mothers of under five children regarding vaccine preventable diseases and to impart the correct information through information booklet to prevent vaccine preventable diseases among under five children and contribute to the health of the future citizens.

\section{OBJECTIVES OF THE STUDY}

- To assess the knowledge regarding Vaccine Preventable Diseases among mothers of under five children.

- To find out association between knowledge score and demographic variables among mothers of under five children.

- To develop an Information Booklet regarding Vaccine Preventable Diseases.

\section{HYPOTHESIS OF THE STUDY}

$\mathbf{H}_{\mathbf{1}}$ : There will be significant knowledge regarding vaccine preventable diseases among mothers of under five children at 0.05 level of significance.

$\mathbf{H}_{\mathbf{0}}$ : There will be no significant association between knowledge and selected demographic variables regarding vaccine preventable diseases among mother of under five children at 0.05 level of significance.

\section{OPERATIONAL DEFINITION}

- Assess: It refers to gather information about knowledge regarding on vaccine preventable disease.

- Knowledge: It refers to the correct response of the subjects to the items listed in the self-administered knowledge questionnaire regarding meaning, causes, signs and symptoms, complications and immunization of vaccine preventable diseases as evident from the test score.

- Vaccine Preventable Diseases: The seven killer diseases namely Tuberculosis, Poliomyelitis, Diphtheria, Pertussis, Tetanus, hepatitis-B, Measles, which can be prevented by vaccines.

- Mothers of under-five: Mothers of under five years of age children in a selected areas of Primary Health Centre at Jaipur.

- Information booklet: It refers to booklet giving information on meaning, causes, signs and symptoms, complications and immunization of vaccine preventable 


\section{EPRA International Journal of Research and Development (IJRD)

diseases commonly found among under five children.

\section{ASSUMPTION}

- There will be inadequate knowledge among Mothers of under five children regarding vaccine preventable disease.

- The information booklet on "Vaccine preventable disease among mother of under five children" will enhance knowledge regarding vaccine preventable diseases.

\section{DELIMITATION}

- The study is delimited to mothers of under five children in selected primary health centre.

- The study is delimited to 60 mother of under five children at selected primary health centre.

- $\quad$ The study is delimited to those mothers who present at the time of data collection.

\section{RESEARCH METHODOLOGY \\ - RESEARCH APPROACH}

Quantitative research approach is considered appropriate for the present study.

- RESEARCH DESIGN

Descriptive survey design was adopted for this study.

\section{RESEARCH VARIABLE}

Research variables are those variable which are observed a measured in natural setting as they exist without any manipulation in the descriptive study no last effect relationship is examined.

- Independent variables

Knowledge of mothers under five children

- Dependant variables

Vaccine preventable diseases

- Demographic variables

Demographic variables are the characteristics and attributes of the study sample. In my study the demographic variables are Age, religion, type of family, educational status, occupation, family income, number of children, food pattern

\section{POPULATION}

Mother of under five children who are residing in Goner PHC, rural Jaipur District.

\section{SAMPLING SIZE}

In this study, the sample consists 60 mothers of under five children.

\section{SAMPLING TECHNIQUE}

Non-probability purposive sampling technique was used for this study.

\section{RELIABLITY OF THE TOOL}

The reliability was established by using Kuder-Richardson Formula 20 (KR-20) formula and it is found to be reliable ( $\mathrm{r}=$ 0.782).

\section{MAJOR FINDING OF THE STUDY}

Table 1 Depicted that of mothers participated in the study, age below 25, $(25,41.7 \%)$, type of family nuclear $(43,70 \%)$, number of children two $(32,53.3 \%)$, Education graduate (20, 33.3\%), Occupation House wife (47, 78.3\%), Monthly income 10 to $15000(33,55 \%)$, source of education friend and family $(52,86.7 \%)$.

Table 2 Depicted that the majority the above table shows the level of knowledge of 60 mothers of under five children in which (33) $55 \%$ had below average knowledge, (18) $30 \%$ had average knowledge and (9) $15 \%$ of them had above average knowledge regarding vaccine preventable diseases.

Table 3 Depicted shows that the knowledge score of mothers textile according to the different aspects the above table represents the mean, SD and mean percentage of aspects of knowledge of mothers of under five children regarding vaccine preventable diseases. The present study shows that the highest mean score of subjects is 18.52 with SD 6.7 and mean percentage of 52.91, was obtained for knowledge regarding vaccine preventable diseases. This indicates that mothers of under five children had poor knowledge regarding vaccine preventable diseases. 


\section{EPRA International Journal of Research and Development (IJRD)

Table 1. Frequency and percentage distribution of demographic variables among mothers $(\mathrm{N}=60)$

\begin{tabular}{|c|c|c|c|c|}
\hline S. No & \multicolumn{2}{|c|}{ Socio-demographic variable } & Frequency & Percentage \\
\hline 1. & Age group & $\begin{array}{l}\text { Below } 25 \\
25-30 \\
31-35 \\
\text { Above } 35\end{array}$ & $\begin{array}{c}21 \\
25 \\
13 \\
1\end{array}$ & $\begin{array}{c}35 \% \\
41.7 \% \\
21.7 \% \\
1.7 \%\end{array}$ \\
\hline 2. & Type of family & $\begin{array}{c}\text { Nuclear } \\
\text { Joint }\end{array}$ & $\begin{array}{l}43 \\
18\end{array}$ & $\begin{array}{l}70 \% \\
30 \%\end{array}$ \\
\hline 3. & Number of children & $\begin{array}{c}\text { One } \\
\text { Two } \\
\text { Three } \\
\text { Four and above }\end{array}$ & $\begin{array}{c}17 \\
32 \\
7 \\
4\end{array}$ & $\begin{array}{c}28.3 \% \\
53.3 \% \\
11.7 \% \\
6.7 \%\end{array}$ \\
\hline 4. & Education & $\begin{array}{c}\text { No formal education } \\
\text { Primary } \\
\text { Secondary } \\
\text { Graduate and above }\end{array}$ & $\begin{array}{l}10 \\
12 \\
18 \\
20\end{array}$ & $\begin{array}{c}16.7 \% \\
20 \% \\
30 \% \\
33.3 \%\end{array}$ \\
\hline 5. & Occupation & $\begin{array}{c}\text { House wife } \\
\text { Private employee } \\
\text { Government employee }\end{array}$ & $\begin{array}{c}47 \\
11 \\
2\end{array}$ & $\begin{array}{l}78.3 \% \\
18.3 \% \\
3.3 \%\end{array}$ \\
\hline 6. & Monthly income & $\begin{array}{c}\text { Below } 10,000 /- \\
10,001-15,000 /- \\
15,001-20,000 \\
20,001 \text { or above }\end{array}$ & $\begin{array}{c}10 \\
33 \\
15 \\
2\end{array}$ & $\begin{array}{c}16.7 \% \\
55 \% \\
25 \% \\
3.3 \%\end{array}$ \\
\hline 7. & Source of information & $\begin{array}{c}\text { Friends \& family } \\
\text { Mass media } \\
\text { Health education programme }\end{array}$ & $\begin{array}{c}52 \\
7 \\
1\end{array}$ & $\begin{array}{c}86.7 \% \\
12.6 \% \\
1.7 \%\end{array}$ \\
\hline
\end{tabular}

Table 2. Level of knowledge regarding Vaccine preventable diseases $(\mathrm{N}=60)$

\begin{tabular}{|c|c|c|}
\hline Level of knowledge & Frequency & Percentage \\
\hline Poor $(<50 \%)$ & 33 & $55 \%$ \\
\hline Average $(50-70 \%)$ & 18 & $30 \%$ \\
\hline Good $(>75 \%)$ & 9 & $15 \%$ \\
\hline Total & $\mathbf{6 0}$ & $\mathbf{6 0 \%}$ \\
\hline
\end{tabular}

Table No. 3

Mean, standard deviation \& mean percentage of knowledge of mothers of under five children regarding vaccine preventable diseases.

\begin{tabular}{|c|c|c|c|c|}
\hline S.No. & Maximum score & Mean & Mean percentage & Standard Deviation \\
\hline 1 & 35 & 18.52 & 52.91 & 6.7 \\
\hline
\end{tabular}

\section{DISCUSSION}

The level of knowledge of 60 mothers of under five children in which (33) $55 \%$ had below average knowledge, (18) $30 \%$ had average knowledge and (9) $15 \%$ of them had above average knowledge regarding vaccine preventable diseases.

The mean, SD and mean percentage of aspects of knowledge of mothers of under five children regarding vaccine preventable diseases. The present study shows that the highest mean score of subjects is 18.52 with SD 6.7 and mean percentage of 52.91, was obtained for knowledge regarding vaccine preventable diseases. This indicates that mothers of under five children had poor knowledge regarding vaccine preventable diseases.

\section{CONCLUSION}

This chapter deals with the analysis and interpretation of the results of the study. The data gathered and analyzed by using descriptive and inferential statistics. Chi-square test was used to find association between the knowledge score with selected demographic variables. Findings revealed that majority of mothers had below average knowledge regarding vaccine preventable diseases.

\section{REFERENCES}

1. Khan M. E. Avishek hazra "Impact of janani suraksha yojana on selected family health behaviours in rural India" Family health J 2010 Aug, 56 (1): 12-15. 


\section{EPRA International Journal of Research and Development (IJRD) Volume: 7 | Issue: 1 | January 2022 \\ - Peer Reviewed Journal}

2. Panja T. K. Mukhopadhyay DK Sinha $N$ "Are institutional deliveries promoted by Janani Suraksha Yojana in a district of West Bengal, India". Indian J Public Health 2012 Jan - Mar, 56 (1) 69-72.

3. Reja R, Gupta AK, Bhatnager R As- sessment of Knowledge about Immun- ization among Mothers of Under Five Children Attending Immunization in Tertiary Care Hospital in Udaipur. Natl $J$ Community Med 2018; 9 (12): 865-868.

4. IOSR Journal of Nursing and Health Science (IOSR-JNHS) e-ISSN: 2320-1959.p- ISSN: 2320-1940 Volume 5, Issue 4 Ver. II (Jul. - Aug. 2016), PP 22-28. www.iosrjournals.org

5. D’Souza VP, Umarani J. Teaching package improves mothers knowledge on vaccine preventable diseases and vaccination: a Quasi experimental study. Int $J$ Res Med Sci 2014;2:976-82.

6. Dindod SM, Makwana NR, Yadav SB. Knowledge of caretakers about routine immunization and reasons for partial immunization in rural areas of Jamnagar District. Int J Med Public Health 2014;4:57-61.

7. Sanaa M. Ahmed, Tarek A. Abd-El Rahman and Eman S. Masoed. Mothers' awareness and knowledge of under five years children regarding immunization in Minia city Egypt. Life Sci J 2013;10(4):1224-1232]. (ISSN: 1097- 8135). http://www.lifesciencesite.com. 162

8. Dinku B, Bisrat F, Kebede Y, Asegidew B, Fantahun M. Knowledge of mothers on poliomyelitis and other vaccine preventable diseases and vaccination status of children in pastoralist and semi-pastoralist areas of Ethiopia. Ethiop Med J. 2013 Jul;51 Suppl 1:5966. PMID: 24380208. 